\title{
Schwann cell autophagy induced by SAHA, 17-AAG, or clonazepam can reduce bortezomib-induced peripheral neuropathy
}

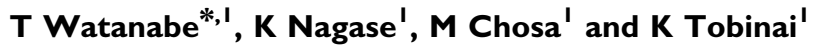 \\ 'Hematology Division, National Cancer Center Hospital, 5-I-I Tsukiji, Chuo-ku, Tokyo 104-0045, Japan
}

\begin{abstract}
BACKGROUND: The proteasome inhibitor bortezomib has improved the survival of patients with multiple myeloma but bortezomibinduced peripheral neuropathy (BiPN) has emerged as a serious potential complication of this therapy. Animal studies suggest that bortezomib predominantly causes pathological changes in Schwann cells. A tractable system to evaluate combination drugs for use with bortezomib is essential to enable continuing clinical benefit from this drug.

METHODS: Rat schwannoma cells were pretreated with vincristine (VCR), histone deacetylase inhibitors, anticonvulsants, or a heatshock protein 90 (HSP90) inhibitor. To then monitor aggresome formation as a result of proteasome inhibition and the activation of chaperone-mediated autophagy (CMA), we performed double-labelling immunofluorescent analyses of a cellular aggregation-prone protein marker.

RESULTS: Aggresome formation was interrupted by VCR, whereas combination treatments with bortezomib involving suberoylanilide hydroxamic acid, I7-allylamino- 17-demethoxy-geldanamycin, or clonazepam appear to facilitate the disposal of unfolded proteins via CMA, inducing HSP70 and lysosome-associated membrane protein type 2A (LAMP-2A).

CONCLUSIONS: This schwannoma model can be used to test BiPN-reducing drugs. The present data suggest that aggresome formation in Schwann cells is a possible mechanism of BiPN, and drugs that induce HSP70 or LAMP-2A have the potential to alleviate this complication. Combination clinical trials are warranted to confirm the relevance of these observations.

British Journal of Cancer (2010) 103, I580-1587. doi:I0.1038/sj.bjc.6605954 www.bjcancer.com

Published online 19 October 2010

(c) 2010 Cancer Research UK
\end{abstract}

Keywords: autophagy; multiple myeloma; neuropathy; proteasome inhibitors

The development of novel agents, such as proteasome inhibitors and immunomodulatory drugs has improved the survival outcome for multiple myeloma (MM) patients (Kumar et al, 2008). However, the incidence of peripheral neuropathy (PN) has emerged as a significant problem in the new therapeutic era for MM (Richardson et al, 2006, 2009b; Argyriou et al, 2008). In younger patients with $\mathrm{MM}$, primary treatments have included vincristine (VCR), doxorubicin, and dexamethasone, and also high-dose therapy with melphalan supported by autologous stem cell transplantation. However, in some of these patients, VCR treatments have caused PN. Moreover, bortezomib was the first proteasome inhibitor to be approved for the treatment of relapsed/ refractory as well as newly diagnosed MM patients (Richardson et al, 2003; San Miguel et al, 2008). However, this treatment can cause peripheral nerve damage leading to the development of bortezomib-induced peripheral neuropathy (BiPN). Owing to these adverse effect, bortezomib will be discontinued even in patients that respond well to this drug. Not surprisingly, bortezomib has recently become one of the mainstays in ongoing clinical trials of combination therapies for MM.

*Correspondence: Dr T Watanabe; E-mail: takawata@ncc.go.jp Revised 10 September 2010; accepted 2I September 2010; published online 19 October 2010
A couple of recent studies have reported neurophysiological and pathological findings for bortezomib administration in animal models (Cavaletti et al, 2007; Bruna et al, 2010; Meregalli et al, 2010). Another histopathological study in rats reported that bortezomib did not affect neurons but did cause damage to Schwann cells (Cavaletti et al, 2007). Another report has however shown that alterations to Schwann cells might be a secondary effect of bortezomib (Bruna et al, 2010). At present, treatments for BiPN are lacking, although anticonvulsants have been administered to MM patients with this disorder (Richardson et al, 2006; Argyriou et $a l, 2008)$. In addition, although a dose-modification guideline for BiPN has been published (Richardson et al, 2009b), it is difficult to accurately evaluate neurotoxicity in patients during bortezomib therapy and thus determine when treatment should discontinue. Hence, combination bortezomib treatments for MM involving agents that function as prophylactics against BiPN, rather than drugs that treat BiPN, are highly desirable. However, there are currently few (if any) investigative tools available to develop such therapies as the molecular mechanisms underlying BiPN remain to be elucidated.

To elucidate the molecular mechanisms underpinning the onset of BiPN in our current study, we first reviewed previous reports on neurodegenerative diseases in which protein aggregates are responsible for the cellular toxicity. When the activity of proteasome is inhibited, misfolded proteins will form aggregates 
known as aggresomes (Johnston et al, 1998). Aggresomes were initially described as inclusion bodies in the cells of patients with neurodegenerative diseases (Kopito, 2000) such as amyotrophic lateral sclerosis (Bruijn et al, 1998; Mezey et al, 1998), Parkinson's disease (Mezey et al, 1998), and Huntington's disease (Bennett et al, 2007). In our present experiments, we employed a schwannoma cell system to monitor aggresome formation after treatment with bortezomib. Furthermore, we examined whether additional treatments could reduce the number and size of these aggregates and thus potentially suppress the onset of BiPN.

\section{MATERIALS AND METHODS}

\section{Schwann cell pretreatment and bortezomib treatment}

A rat schwannoma cell line RT4-D6P2T (purchased from ATCC, Manassas, VA, USA, on 28 May 2007) was cultured in Dulbecco's modified Eagle's medium (Sigma-Aldrich, St Louis, MO, USA) containing 10\% FBS (Bioserum, Victoria, Australia). RT4-D6P2T cells were cultured for less than 2 months after reconstitution from stocks, which were frozen upon receipt from the ATCC. The cells had been validated by the supplier using DNA fingerprinting and no additional authentication was performed in our laboratory. The morphology of the RT4-D6P2T cells showed no changes over the course of the study.

At 1 day before pretreatment, the RT4-D6PT2 cells were plated at a density of $5 \times 10^{4}$ cells per well on four-well chamber slides. They were then either untreated or pretreated with 40 nM VCR (SigmaAldrich) for $1 \mathrm{~h}$ or pretreated for $24 \mathrm{~h}$ with either $5 \mu \mathrm{M}$ suberoylanilide hydroxamic acid (SAHA; Merck \& Co. Inc., Whitehouse Station, NJ, USA), $0.5 \mu \mathrm{m}$ 17-allylamino-17-demethoxy-geldanamycin (17-AAG; Sigma-Aldrich), $50 \mathrm{~nm}$ clonazepam (CZP; SigmaAldrich), or $6 \mathrm{~mm}$ valproic acid (VPA; Sigma-Aldrich). The dose of each reagent was determined by its half maximal inhibitory value $\left(\mathrm{IC}_{50}\right)$. For VCR pretreatments, the cells were washed twice with PBS: $2.68 \mathrm{~mm} \mathrm{KCl}, 1.47 \mathrm{mM} \mathrm{KH}_{2} \mathrm{PO}_{4}, 136.89 \mathrm{~mm} \mathrm{NaCl}$, and $8.10 \mathrm{~mm}$ $\mathrm{Na}_{2} \mathrm{HPO}_{4}$ (Dainippon Sumitomo Pharma Co. Ltd., Osaka, Japan) before the addition of $40 \mathrm{~nm}$ bortezomib (Millennium Pharmaceuticals, Cambridge, MA, USA) for $3 \mathrm{~h}$. Following pretreatment with other reagents, the cells were not washed before the 3-h treatment with $40 \mathrm{~nm}$ bortezomib. As a final step, the cells were washed twice with PBS, incubated for a further $24 \mathrm{~h}$, and then fixed.
A

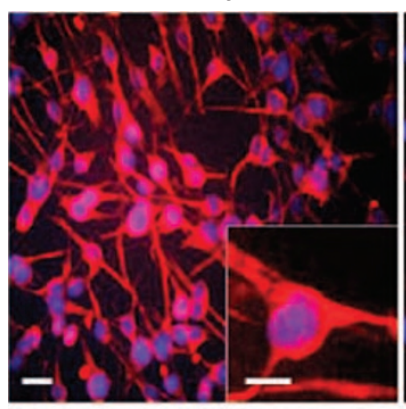

B
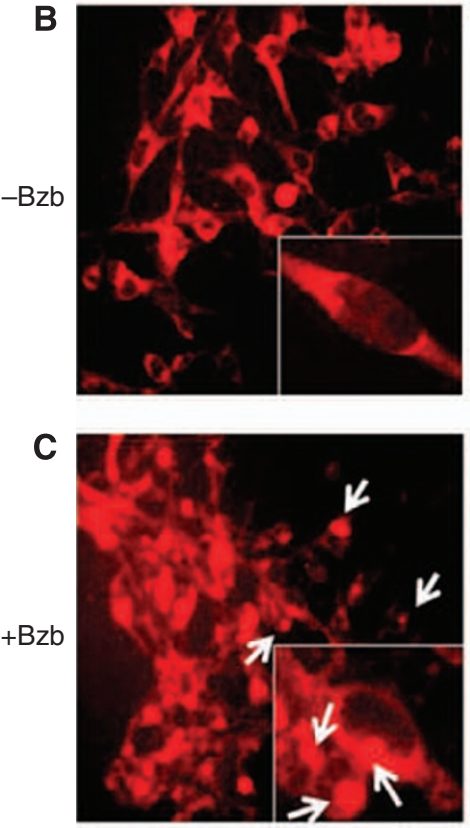

$+\mathrm{Bzb}$
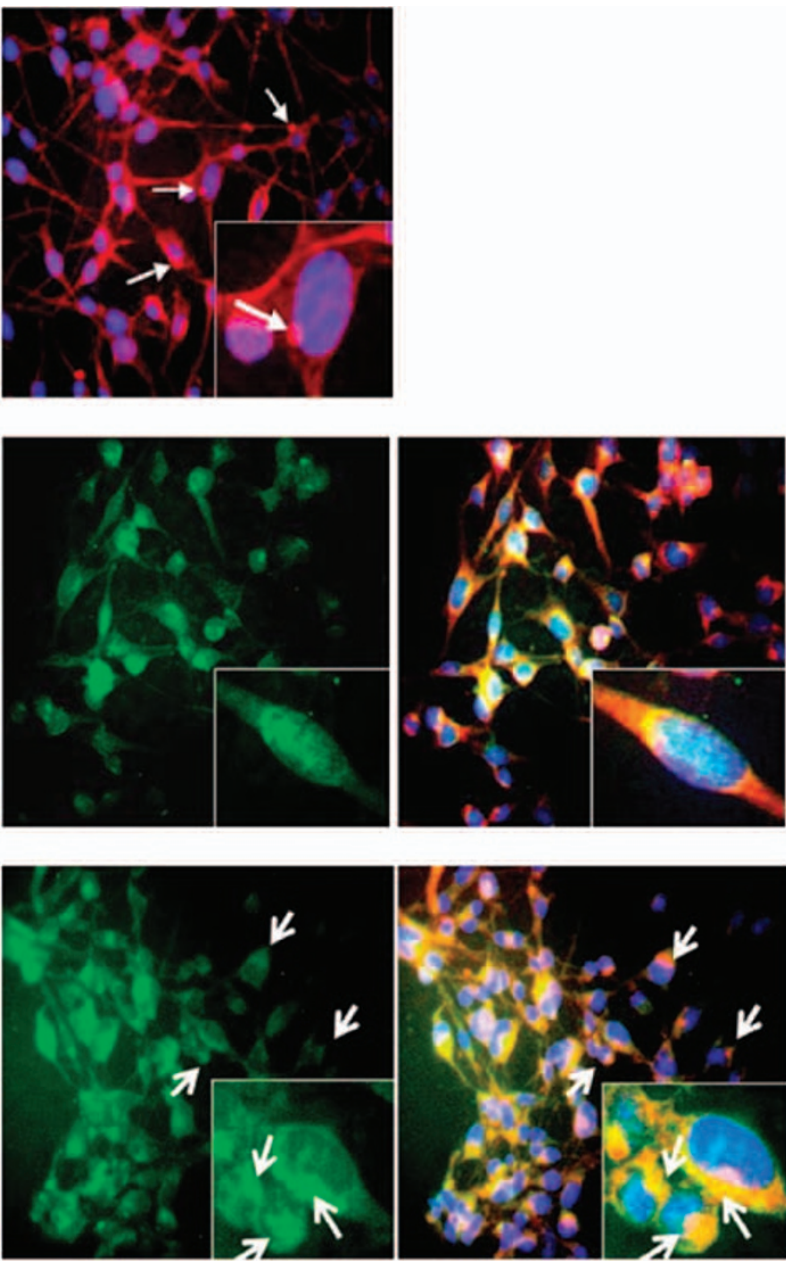

Figure I Bortezomib induces aggresome formation at the microtubule-organising centres (MTOCs) of Schwann cells. (A) In untreated RT4-D6P2T cells, $\gamma$-tubulin is distributed homogeneously throughout the cytoplasm (left panel). In bortezomib (Bzb)-treated cells, aggresomes form as distinct pericentriolar structures (arrows) with weak staining in the cytoplasm (right panel). Insets in the right panel show the juxtanuclear rounded structures evident at higher magnification. (B) Untreated RT4-D6P2T cells contain dynein (red), which is distributed homogeneously in the cytoplasm with predominant localisation in the perinuclear region, and vimentin (green), which is distributed diffusely throughout the cytoplasm and above the nuclei. (C) In bortezomib-treated cells, dynein (red) and vimentin (green) appear as rounded structures at the MTOC (arrows) and are colocalised in the region adjacent to the nuclei (yellow signals in the merged image of both fluorochrome channels. Bar, $20 \mu \mathrm{M}$. -Bzb, untreated; + Bzb, bortezomib treated. 


\section{Immunohistochemical analysis}

The RT4-D6P2T cells were fixed with PBS containing 4\% paraformaldehyde for $10 \mathrm{~min}$ at $4^{\circ} \mathrm{C}$, washed with TBS $(20 \mathrm{~mm}$ Tris and $500 \mathrm{~mm} \mathrm{NaCl}(\mathrm{pH} 7.4)$ ) with $0.1 \%$ IGEPAL CA-630 (Fluka, Buchs, Switzerland) for $3 \times 5 \mathrm{~min}$, fixed in methanol for $10 \mathrm{~min}$ at $4{ }^{\circ} \mathrm{C}$, and blocked with PBS containing 4\% BSA (Sigma-Aldrich) for $30 \mathrm{~min}$ at room temperature. The cells were then incubated overnight at $4{ }^{\circ} \mathrm{C}$ with primary antibodies diluted at a ratio of $1: 50$ in PBS with $4 \%$ BSA ( $\gamma$-tubulin (Sigma-Aldrich), dynein (SigmaAldrich), vimentin (Santa Cruz Biotechnology, Santa Cruz, CA, USA), heat-shock protein 70 (HSP70; Santa Cruz Biotechnology), peripheral myelin protein 22 (PMP22; Millipore, Bedford, MA, USA), and lysosome-associated membrane protein type $2 \mathrm{~A}$ (LAMP-2A; Abcam, Cambridge, MA, USA)). The cells were then washed $3 \times 5 \mathrm{~min}$ in TBS with $0.1 \%$ IGEPAL CA-630 and incubated with secondary antibodies diluted at a ratio of $1: 100$ in PBS with
$4 \%$ BSA, for $1 \mathrm{~h}$ at room temperature (Alexa Fluor 488-conjugated chicken anti-rabbit IgG and Alexa Fluor 555-conjugated goat antimouse IgG (Molecular Probes, Eugene, OR, USA)). After a further washing for $3 \times 5 \mathrm{~min}$ in TBS with $0.1 \%$ IGEPAL CA-630, the cells were mounted on slides with VECTASHIELD (Vector Laboratories, Burlingame, CA, USA). We note that all washes were performed at room temperature. Images of the cells were captured on a laser scanning confocal microscope BZ-8000 (Keyence, Osaka, Japan) and analysed by BZ-Analyser software (Keyence). The thickness of the optical sections analysed was $0.4 \mu \mathrm{m}$.

\section{Quantification of aggresomes and round structures outside of the Schwann cells}

Aggresomes and round structures outside of the cells were identified by the colocalisation of PMP22 and $\gamma$-tubulin, counted
A

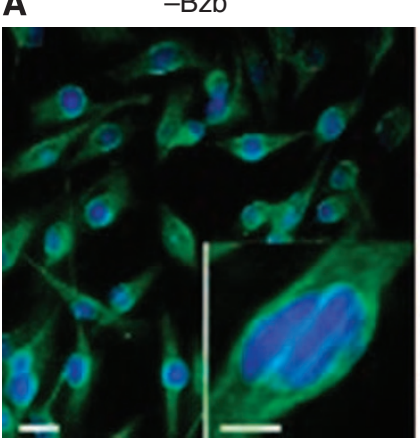

B

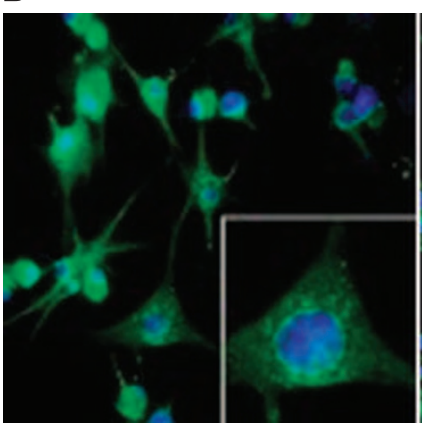

$\mathbf{F}$

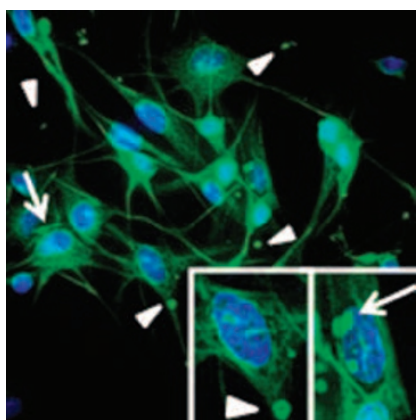

$+\mathrm{Bzb}$

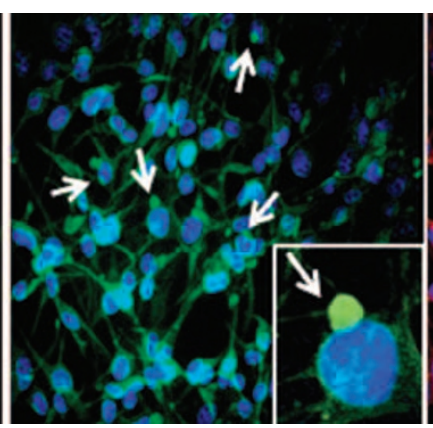

C $+\mathrm{SAHA} \rightarrow \mathrm{Bzb}$

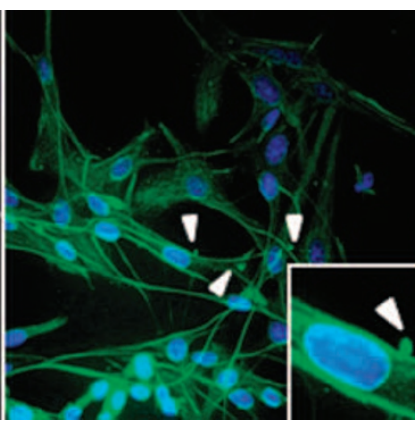

$+\mathrm{Bzb}$

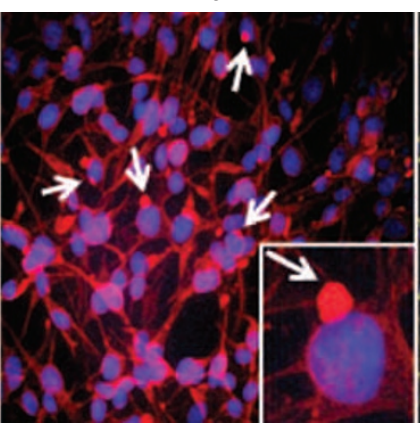

D $\quad+\mathrm{CZP} \rightarrow \mathrm{Bzb}$

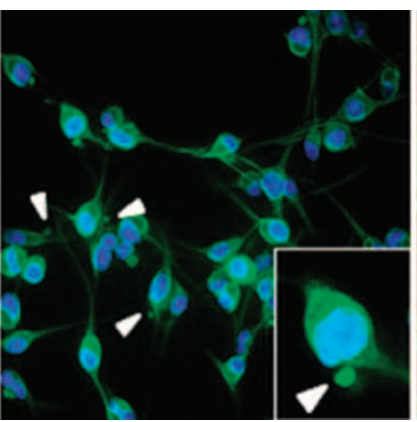

$+\mathrm{Bzb}$

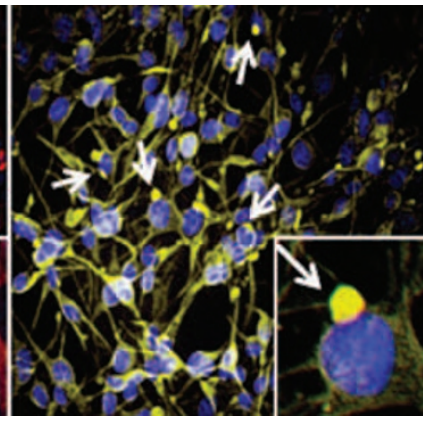

E $\quad+17-A A G \rightarrow B z b$

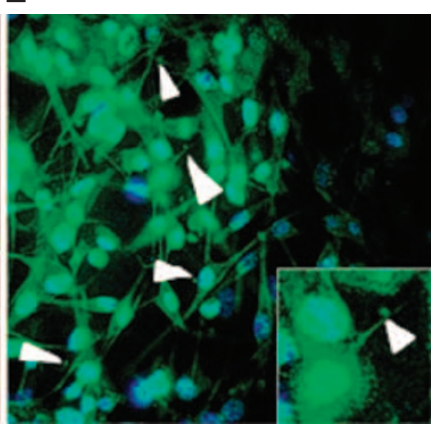

Figure 2 Vincristine (VCR) abrogates aggresome formation and in a combination treatment with bortezomib augments the exocytosis of endogenous misfolded proteins. (A) Peripheral myelin protein 22 (PMP22) is homogeneously distributed throughout the cytoplasm of RT4-D6P2T cells before treatment with bortezomib (left panel). After treatment with bortezomib (Bzb), PMP22 appears to undergo retrograde transport towards the MTOC where it forms perinuclear aggresomes (arrows, middle panel, green signals) and colocalises with $\gamma$-tubulin (arrows, middle panel, red signals). A merged image of both fluorophores is shown in the far right panel (yellow signal). (B) Following pretreatment with VCR, a microtubule depolymerisation agent, PMP22 signals are evident at multiple sites in a granular pattern of aggregates throughout the cytoplasm, most notably in the perikaryon. Cells pretreated with (C) suberoylanilide hydroxamic acid (SAHA), a known histone deacetylase inhibitor (HDACi), or (D) clonazepam (CZP), an anticonvulsant, and (E) 17-allylamino- 17-demethoxy-geldanamycin (I7-AAG), a HSP90 inhibitor, fail to form aggresomes, but instead form rounded structures outside of the cell (arrowheads), which are smaller than the perinuclear aggresomes. (F) Pretreatment with valproic acid (VPA) causes the appearance of similar rounded structures outside of the cells (arrowheads) in addition to juxtanuclear aggresomes (arrows). 
in triplicate from 200 cells, and expressed as a percentage of the total cells.

\section{Growth inhibition assay of MM cells}

The human MM cell lines, MM.1S, RPMI8226 (purchased from ATCC), and KMS-18 (kindly provided by Dr T Otsuki, Department of Hygiene, Kawasaki Medical School, Kurashiki, Japan) were maintained in RPMI1640 (Sigma-Aldrich) containing 10\% FBS. The growth-inhibitory effects upon MM cells were determined using a 3-(4, 5-dimethyl-2-thiazolyl)-2,5-diphenyl-2H-tetrazolium bromide (MTT) assay (Sigma-Aldrich). At 1 day before treatment, $9.0 \times 10^{4}$ cells per $90 \mu \mathrm{l}$ aliquot were cultured in 96 -well plates (Sumitomo Bakelite, Higashikangawa, Japan) in triplicate at $37^{\circ} \mathrm{C}$. Cells were either untreated or pretreated for $24 \mathrm{~h}$ with the same concentration of each reagent used with the RT4-D6P2T cells except for VCR. The cells were then cultured further with varying concentrations (from 0.5 to $3 \mathrm{nM}$ ) of bortezomib for $48 \mathrm{~h}$. Optical densities (ODs) at 570 and $630 \mathrm{~nm}$ were measured using a multiplate reader. Stock MTT was added to each of the wells in the assay, and the plates were further incubated at $37^{\circ} \mathrm{C}$ for $5 \mathrm{~h}$. Dimethyl sulphoxide (Sigma-Aldrich) was added to all wells and mixed thoroughly. After a few minutes at room temperature to ensure that all formazan crystals were dissolved, the plates were read on a SpectroMax 340 $\mathrm{PC}^{384}$ VersaMax (Molecular Devices, Sunnyvale, CA, USA), using a test wavelength of $570 \mathrm{~nm}$ and a reference wavelength of $630 \mathrm{~nm}$. Cell growth (\%) was calculated as follows: $\left(\mathrm{OD}_{630}-\mathrm{OD}_{570}\right.$ of the samples/OD $\mathrm{OD}_{630}-\mathrm{OD}_{570}$ of the control) $\times 100$.

\section{RESULTS}

\section{Aggresomes form at MTOC following proteasome inhibition in Schwann cells}

A diffuse expression pattern of $\gamma$-tubulin, a protein that adheres to the centrosome (Dictenberg et al, 1998), was observed in the cytoplasm of RT4-D6P2T cells. Following a 3-h treatment with $40 \mathrm{~nm}$ bortezomib, however, $\gamma$-tubulin staining in the cytoplasm became weak and coalesced to form round structures in the juxtanuclear area (Figure 1A). Similarly, the dynein and vimentin proteins became rounded and colocalised in region adjacent to the nucleus after exposure to bortezomib (Figure 1C).

\section{Vincristine abrogates bortezomib-induced aggresome formation and combination treatments augment the exocytosis of endogenous misfolded proteins from Schwann cells}

We next examined whether endogenous misfolded proteins destined to be processed by the ubiquitin-proteasome system could be induced to aggregate and undergo retrograde transport towards the microtubule-organising center (MTOC) upon proteasome inhibition. To accomplish this, we employed the cellular marker PMP22, a short-lived glycoprotein present in Schwann cells (Fortun et al, 2003). Following bortezomib treatment, PMP22 showed a distinct juxtanuclear and rounded appearance and colocalised with $\gamma$-tubulin to form aggresomes (Figure 2A), as previously reported (Fortun et al, 2003). Interestingly, treatments with VCR completely abrogated the bortezomib-induced accumulation of PMP22, which was instead observed as numerous spots in the perikaryon (Figure $2 \mathrm{~B}$ ).

We next analysed whether treatments with a combination of reagents could reduce aggresome formation. Intriguingly, pretreatment with the histone deacetylase inhibitor (HDACi) SAHA (Figure 2C), the anticonvulsant CZP (Figure 2D), or the HSP90 inhibitor 17-AAG (Figure 2E) caused the appearance of round structures, which were smaller than aggresomes, outside of the

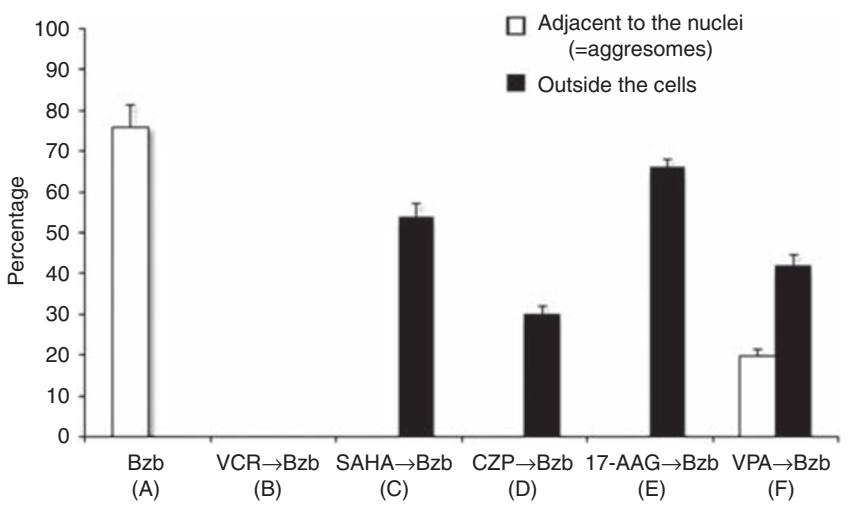

Figure 3 The percentages of round structures adjacent to the nuclei (i.e., aggresomes) and outside the cells were calculated from images showing the colocalisation of PMP22 and $\gamma$-tubulin (yellow signals in the far right panel in Figure 2A). These numbers were measured in triplicate and are expressed as the means \pm s.d. The letters in parentheses under the treatment categories correspond to the images above.

cells and with no juxtanuclear aggresomes (Figure 3). In contrast, pretreatment with VPA, also an anticonvulsant and an HDACi, caused the appearance of rounded structures outside of the cells in addition to juxtanuclear aggresomes (Figures $2 \mathrm{~F}$ and 3 ).

Chaperone-mediated autophagy is responsible for the enhanced exocytosis of misfolded proteins in Schwann cells during proteasome inhibition

To analyse the molecular mechanisms underlying the enhanced exocytosis of misfolded proteins in Schwann cells, we used an antibodies against the HSP70 chaperone protein and the receptor for chaperone-mediated autophagy (CMA) at the lysosomal membrane (which is a unique isoform of LAMP-2, LAMP-2A) (Cuervo and Dice, 2000; Kaushik et al, 2006). After treatment with SAHA, 17-AAG, or CZP (Figure 4A, B, or C, respectively) followed by bortezomib, HSP70 and LAMP-2A were found to colocalise in structures outside of the cells.

Drugs that protect Schwann cells from aggresome formation due to bortezomib treatment do not disrupt the growth inhibitory effects of bortezomib in myeloma cells

Pretreatments of MM cells with the same drugs used in the RT4-D6P2T cell experiments had few negative effects on the profound growth inhibitory effects of bortezomib (Figure 5).

\section{DISCUSSION}

The findings of our present study using a schwannoma cell model system suggest that aggresome formations caused by proteasome inhibition and the excretion pathways of intracellular misfolded proteins are targets for combination drug candidates that will alleviate the onset of BiPN during bortezomib treatment.

A recent study of skin biopsies has revealed that BiPN manifests as predominantly large fibres (Chaudhry et al, 2008). On the other hand, in some BiPN patients who develop treatment-emergent neuropathy, the underlying cause has been attributed to the impairment of small fibres (Richardson et al, 2006), even though such fibres comprise myelinated $\mathrm{A} \delta$ and unmyelinated $\mathrm{C}$ fibres. In contrast, it has been proposed that $68-85 \%$ of BiPN cases are reversible (Richardson et al, 2009a, b). 
A

HSP70

LAMP-2A
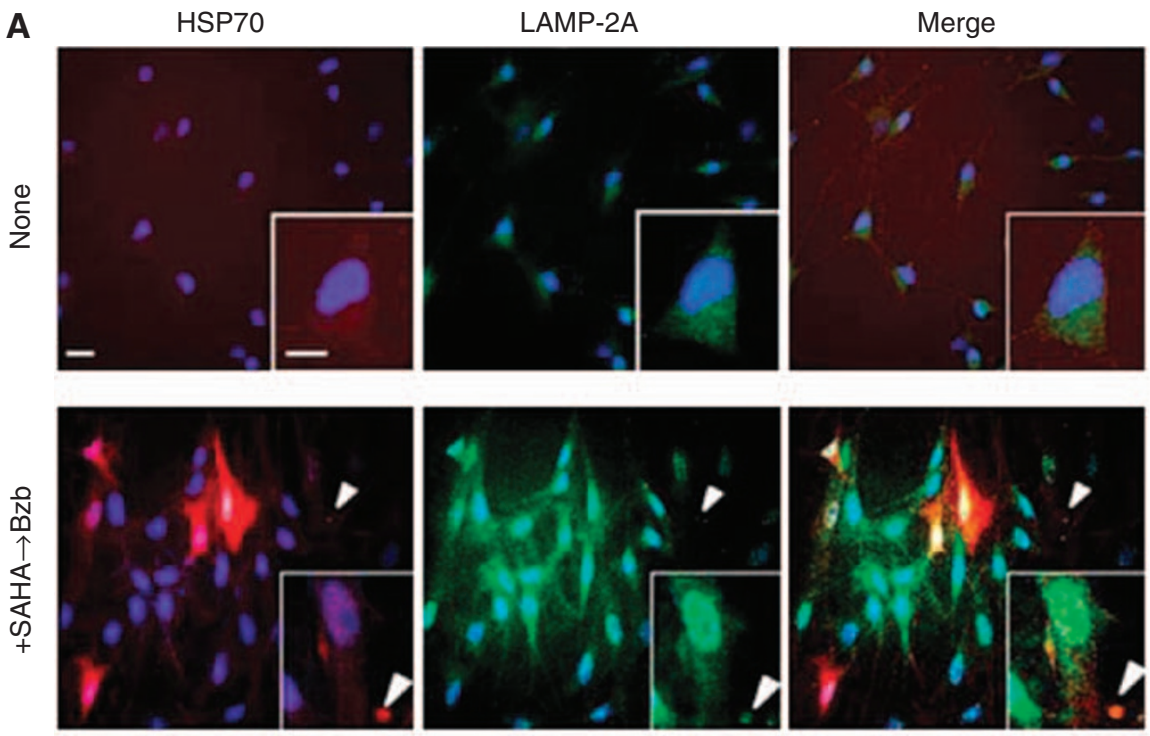

B

HSP70

LAMP-2A

Merge
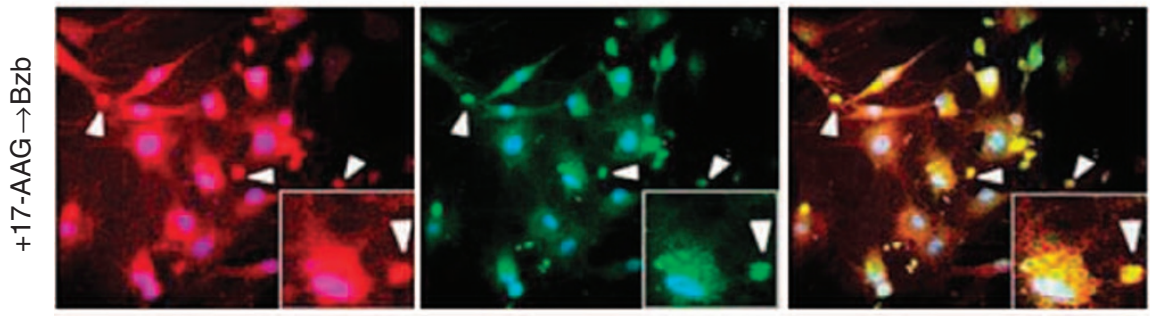

C

LAMP-2A

Merge
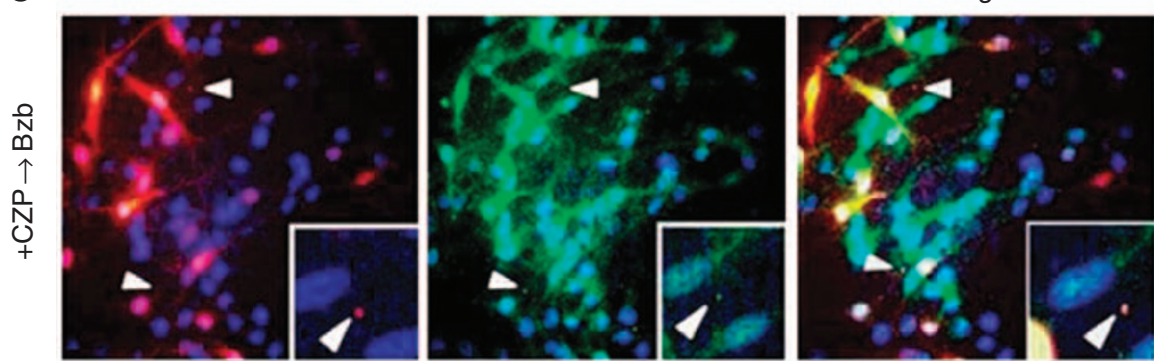

Figure 4 Combination treatments with bortezomib can augment the exocytosis of misfolded proteins through the chaperone-mediated autophagy of Schwann cells. The distributions of HSP70/HSC70 (red), a chaperone protein, and LAMP-2A (green), a lysosomal membrane protein with a specific role in chaperone-mediated autophagy, are shown in response to combination treatments with (A) SAHA, (B) I7-AAG, and (C) CZP. The colocalisation of both proteins is evidenced by the small rounded structures outside of the cells that appear as an orange signal (arrowheads). Bar, $20 \mu \mathrm{M}$.
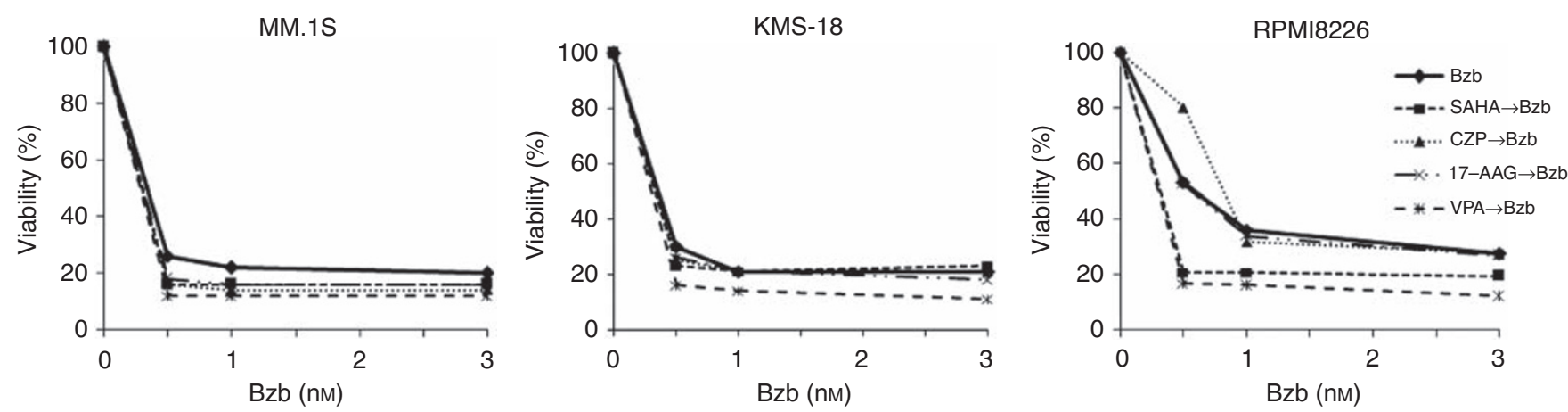

Figure 5 The same combinations used in Figures 2 and 3 do not suppress the growth inhibition of multiple myeloma (MM) cells induced by bortezomib. In MM, cells (MM.IS, KMS-18, and RPMI8226) were treated with bortezomib alone or in combination with SAHA, CZP, I7-AAG, or VPA. The proportion of viable cells after pretreatment with each drug followed by bortezomib treatment is indicated as a percentage of the untreated cells. These numbers were measured in triplicate and are expressed as the means \pm s.d. 
Although it has already been demonstrated that the behaviour of cells of neoplastic origin can differ markedly from normal cells (Scuteri et al, 2006), cell lines are usually more tractable for experimental purpose than primary culture cells. In addition, because BiPN is predominantly sensory (Richardson et al, 2006; Richardson et al, 2009a, b), it would have been desirable to use cell
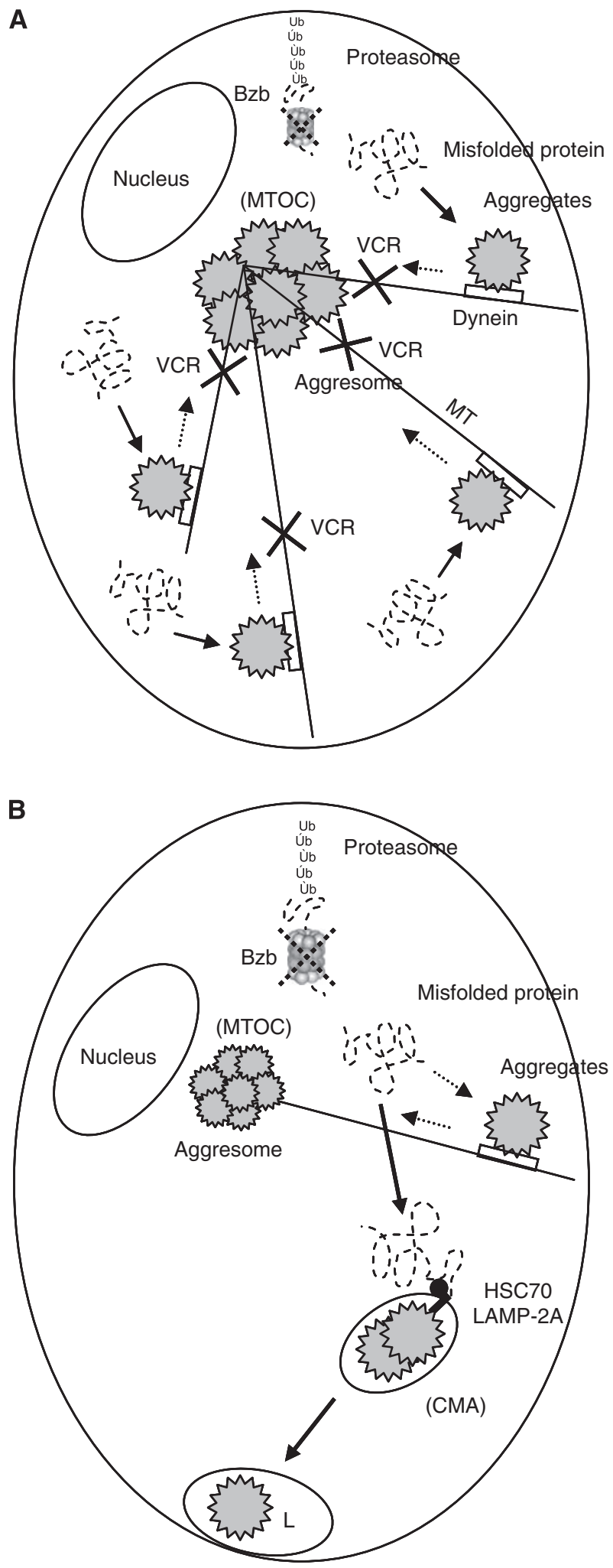

lines that would somewhat mimic the peripheral sensory nerves. No such cells are currently available however and we thus employed schwannoma cells for analysis, which are benign and differentiated tumour cells, rather than neuroblastoma cells used in previous reports (Scuteri et al, 2006; Csizmadia et al, 2008).

Our present data are consistent with previous observations that misfolded proteins form aggregates throughout the cell if they are not degraded by the proteasome (Figure 2B). Furthermore, such aggregates are then transported in a microtubule (MT)-dependent manner to the MTOC on the dynein motor complex (Figure 1C, red) (Johnston et al, 1998; Kopito, 2000; Garcia-Mata et al, 2002). After treatment with bortezomib, it has been shown that vimentin, the most common component of the intermediate filament cytoskeleton (Franke et al, 1978), collapses to form a 'cage' surrounding the aggresome, which then adopts a 'rounded' morphology (Figure 1C, green) (Johnston et al, 1998; García-Mata et al, 1999). Moreover, our observations of aggresome formations with a distinct juxtanuclear spherical appearance that colocalise with $\gamma$-tubulin (Figure 1A, right) after treatment with proteasome inhibitor in Schwann cells corroborate those of a previous study (Fortun et al, 2003). Moreover, our results demonstrating that the fate of intracellular ubiquitinated aggregation-prone proteins may be relevant to the development of BiPN support previous findings for the gene expression profiles of bone marrow cells in MM patients with treatment-emergent BiPN (Richardson et al, 2009b). These authors identified distinct classes of gene transcripts, namely those involved in the initiation and regulation of protein translation, and their results indicated that enriched proteins that are released from MM cells may be toxic to the peripheral nervous system (Richardson et al, 2009b).

PMP22 is associated with a demyelinating PN, Charcot-MarieTooth disease type 1A (Patel et al, 1992), and VCR is contraindicated in patients with this disease. In our present study, we observed that VCR treatment resulted in the dispersion of aggregates in the cytoplasm and no formation of juxtanuclear aggresomes (Figure 2B). In other words, because VCR is an MT-disrupting drug, our result suggests that pretreatment with this agent might increase BiPN by hindering the movement of unfolded proteins along the MTs with dynein motor complexes (Figure 6A). Indeed, other investigators have suggested that the neuropathy produced by VCR treatment may compromise the ability of the patients to receive bortezomib (Kyle and Rajkumar, 2009).

The central aim of our current study was to develop a clinically relevant in vitro system to test drugs that could be combined with bortezomib to reduce the incidence of BiPN. One of the tested candidates was the anticonvulsant VPA, which has been used previously to alleviate the symptoms of painful diabetic neuropathy (Kochar et al, 2004). However, the $6 \mathrm{~mm}$ concentration of VPA used in our experiments is more than 4000 -fold higher than the previously reported clinical dosage (Munster et al, 2009). Furthermore, our results suggest that VPA may be less effective in

Figure $\mathbf{6}$ Schematic representation of the disruption of aggresome formation (A) and chaperone-mediated autophagy (CMA) (B). (A) Small peripherally formed aggregates are transported along the microtubule (MT) tracks by retrograde motors (i.e., dyneins) to a juxtanuclear pericentriolar location, the MT organisation centre (MTOC). 'Xvcr' indicates that VCR pretreatment before the administration of bortezomib (Bzb) hinders aggresome formation. This is likely because VCR is an MT-disrupting drug and the aggregates would be unable to move along the MTs on the dyneins towards the MTOC. (B) SAHA, CZP, I7-AAG, and VPA have the potential to enhance the expression of HSP70/heat-shock cognate protein of $70 \mathrm{Kd}$ (HSC70), which recognises the specific motif targeted by CMA in its substrate proteins. Lysosome-associated membrane protein type 2A (LAMP-2A) is a unique receptor for CMA. Aggregated proteins are delivered from the cytoplasm out of the cells through lysosomes $(\mathrm{L})$ by $\mathrm{CMA}$. 
reducing BiPN than other HDACi's such as SAHA or anticonvulsants like CZP. Indeed, pretreatment with VPA followed by bortezomib was found to elicit juxtanuclear aggresome formation in addition to the formation of rounded structures outside of the cells (Figures 2F and 3). On the other hand, SAHA has been shown previously to disrupt bortezomib-induced aggresome formation in MM cells (Nawrocki et al, 2008) as a result of the destruction of HDAC6, which promotes aggresome inclusion of misfolded polyubiquitylated proteins on the dynein motor complexes along the MTs (Kawaguchi et al, 2003). The $5 \mu \mathrm{M}$ concentration of SAHA used in this study was two- to five-fold higher than the clinically usable dose in our previous pharmacokinetic analyses of phase I trials of oral SAHA (Watanabe et al, 2010). However, the $40 \mathrm{~nm}$ quantity of bortezomib used in this study is equivalent to that observed in our earlier study (Ogawa et al, 2008), and the $40 \mathrm{~nm}$ of VCR, $50 \mathrm{nM}$ of CZP, and $0.5 \mu \mathrm{M}$ of 17-AAG used in our analyses are equivalent to the doses for these compounds reported in other studies (Goetz et al, 2005; Corona et al, 2008; dos Santos et al, 2009, respectively).

The results of our current analyses shown in Figure 4 suggest that following pretreatment with the candidate drugs, the aggregated proteins are discarded outside of the cells by CMA (Kaushik et al, 2006). The evidence in support of CMA as the mechanism of disposal in this case is that the antibody used in our experiments does not distinguish between HSP70 and the heatshock cognate protein of $70 \mathrm{Kd}$ (HSC70) (Shen et al, 2009), which recognises the CMA-targeting motif in the substrate protein (Agarraberes et al, 1997). To our knowledge, the role of CMA either under conditions of proteasome inhibition or in the nervous system has never been previously reported. However, HSP70 and LAMP-2A, a specific receptor for CMA, were found in our analysis to be colocalised in the rounded structures including misfolded proteins (Figure 4). By inducing the chaperone protein, we speculate that these agents may promote an additional degradation pathway via lysosomes to excrete aggregated proteins from Schwann cells. This is different from the retrograde transport of aggregated proteins to form aggresomes along MTs from the periphery in the cytoplasm to the MTOC, thus aiding cells in the disposal of aggregated proteins (Figure 6B).

The overexpression of HSP70, which could be induced by SAHA alone in our experiments (Figure $4 \mathrm{~A}$, data not shown), is a

\section{REFERENCES}

Agarraberes FA, Terlecky SR, Dice JF (1997) An intralysosomal hsp70 is required for a selective pathway of lysosomal protein degradation. J Cell Biol 137: 825-834

Argyriou AA, Iconomou G, Kalofonos HP (2008) Bortezomib-induced peripheral neuropathy in multiple myeloma: a comprehensive review of the literature. Blood 112: $1593-1599$

Badros A, Burger AM, Philip S, Niesvizky R, Kolla SS, Goloubeva O, Harris C, Zwiebel J, Wright JJ, Espinoza-Delgado I, Baer MR, Holleran JL, Egorin MJ, Grant S (2009) Phase I study of vorinostat in combination with bortezomib for relapsed and refractory multiple myeloma. Clin Cancer Res 15: 5250-5257

Bali P, Pranpat M, Bradner J, Balasis M, Fiskus W, Guo F, Rocha K, Kumaraswamy S, Boyapalle S, Atadja P, Seto E, Bhalla K (2005) Inhibition of histone deacetylase 6 acetylates and disrupts the chaperone function of heat shock protein 90: a novel basis for antileukemia activity of histone deacetylase inhibitors. J Biol Chem 280: $26729-26734$

Bennett EJ, Shaler TA, Woodman B, Ryu K-Y, Zaitseva TS, Becker CH, Bates GP, Schulman H, Kopito RR (2007) Global changes to the ubiquitin system in Huntington's disease. Nature 448: 704-708

Bruijn LI, Houseweart MK, Kato S, Anderson KL, Anderson SD, Ohama E, Reaume AG, Scott RW, Cleveland DW (1998) Aggregation and motor neuron toxicity of an ALS-linked SOD1 mutant independent from wildtype SOD1. Science 281: $1851-1854$ well-described consequence of HSP90 inhibition by 17-AAG (Guo et al, 2005). This finding is consistent with the results from series of previous reports, which showed that a pan-HDACi similar to SAHA inhibits the HSP90 deacetylase HDAC6 (Bali et al, 2005), and that acetylation of HSP90 releases heatshock factor-1 from HSP90 (Zou et al, 1998) and consequently induces HSP70 expression (Morimoto, 1998). Furthermore, our present in vitro data may corroborate the results of a clinical trial with bortezomib and tanespimycin (a cremophor-based formulation of 17-AAG) in which BiPN was reduced (Mitsiades et al, 2009; Richardson et al, 2010). In the case of SAHA, a multicentre phase I trial in combination with bortezomib for relapsed or refractory MM patients has been performed and only mild PN was reported (Badros et al, 2009). Another case series has reported gastrointestinal tract events only without discontinuation or dose adjustments of either agent (Mazumder et al, 2010). Interestingly, HSP70 has also been show to have a major role in the cellular defence against the toxic effects of misfolded proteins in neurodegenerative diseases such as amyotrophic lateral sclerosis (Gifondorwa et al, 2007), Parkinson's disease (Roodveldt et al, 2009), and Huntington's disease (Wacker et al, 2009).

As the binding of substrates, that is, misfolded proteins, to LAMP-2A is the limiting step for degradation via CMA (Cuervo and Dice, 1996), the induction of LAMP-2A as well as HSP70/ HSC70 may be a promising marker for screening drugs that may reduce $\mathrm{BIPN}$.

In summary, although the results of our present study are preliminary and in vitro only, our data suggest that the combination of bortezomib and SAHA, 17-AAG, or CZP has the potential to reduce BiPN. As bortezomib is currently an important component of combination treatment for $\mathrm{MM}$, our in vitro system may allow MM patients to continue to benefit from bortezomib in the future.

\section{ACKNOWLEDGEMENTS}

This work was supported by a grant-in-aid for Cancer Research (21-8) from the Ministry of Health, Labour and Welfare of Japan (T Watanabe).
Bruna J, Udina E, Alé A, Vilches JJ, Vynckier A, Monbaliu J, Silverman L, Navarro X (2010) Neurophysiological, histological and immunohistochemical characterization of bortezomib-induced neuropathy in mice. Exp Neurol 223: 599-608

Cavaletti G, Gilardini A, Canta A, Rigamonti L, RodriguezMenendez V, Ceresa C, Marmiroli P, Bossi M, Oggioni N, D’Incalci M, De Coster R (2007) Bortezomib-induced peripheral neurotoxicity: a neurophysiological and pathological study in the rat. Exp Neurol 204: $317-325$

Chaudhry V, Cornblath DR, Polydefkis M, Ferguson A, Borrello I (2008) Characteristics of bortezomib- and thalidomide-induced peripheral neuropathy. J Peripher Nerv Syst 13: 275-282

Corona G, Casetta B, Sandron S, Vaccher E, Toffoli G (2008) Rapid and sensitive analysis of vincristine in human plasma using on-line extraction combined with liquid chromatography/tandem mass spectrometry. Rapid Commun Mass Spectrom 22: 519-525

Csizmadia V, Raczynski A, Csizmadia E, Fedyk ER, Rottman J, Alden CL (2008) Effect of an experimental proteasome inhibitor on the cytoskeleton, cytosolic protein turnover, and induction in the neuronal cells in vitro. Neurotoxicology 29: $232-243$

Cuervo AM, Dice JF (1996) A receptor for the selective uptake and degradation of proteins by lysosomes. Science 273: $501-503$

Cuervo AM, Dice JF (2000) Unique properties of lamp2a compared to other lamp2 isoforms. J Cell Sci 113: $4441-4450$ 
Dictenberg JB, Zimmerman W, Sparks CA, Young A, Vidair C, Zheng Y, Carrington W, Fay FS, Doxsey SJ (1998) Pericentrin and $\gamma$-tubulin form a protein complex and are organized into a novel lattice at the centrosome. J Cell Biol 141: $163-174$

dos Santos FM, Gonçalves JCS, Caminha R, da Silveira GE, Neves CS, Gram KR, Ferreira CT, Jacqmin P, Noël F (2009) Pharmacokinetic/ pharmacodynamic modeling of psychomotor impairment induced by oral clonazepam in healthy volunteers. Ther Drug Monit 31: 566-574

Fortun J, Dunn Jr WA, Joy S, Li J, Notterpek L (2003) Emerging role for autophagy in the removal of aggresomes in Schwann cells. J Neurosci 23: $10672-10680$

Franke WW, Schmid E, Osborn M, Weber K (1978) Different intermediatesized filaments distinguished by immunofluorescence microscopy. Proc Natl Acad Sci USA 75: 5034-5038

García-Mata R, Bebök Z, Sorscher EJ, Sztul ES (1999) Characterization and dynamics of aggresome formation by a cytosolic GFP-chimera. J Cell Biol 146: $1239-1254$

Garcia-Mata R, Gao Y-S, Sztul ES (2002) Hassles with taking out the garbage: aggravating aggresomes. Traffic 3: 388-396

Gifondorwa DJ, Robinson MB, Hayes CD, Taylor AR, Prevette DM, Oppenheim RW, Caress J, Milligan CE (2007) Exogenous delivery of heat shock protein 70 increases lifespan in a mouse model of amyotrophic lateral sclerosis. J Neurosci 27: $13173-13180$

Goetz MP, Toft D, Reid J, Ames M, Stensgard B, Safgren S, Adjei AA, Sloan J, Atherton P, Vasile V, Salazaar S, Adjei A, Croghan G, Erlichman C (2005) Phase I trial of 17-allylamino-17-demethoxygeldanamycin in patients with advanced cancer. J Clin Oncol 23: 1078- 1087

Guo F, Rocha K, Bali P, Pranpat M, Fiskus W, Boyapalle S, Kumaraswamy S, Balasis M, Greedy B, Armitage ESM, Lawrence N, Bhalla K (2005) Abrogation of heat shock protein 70 induction as a strategy to increase antileukemia activity of heat shock protein 90 inhibitor 17-allylaminodemethoxy geldanamycin. Cancer Res 65: 10536-10544

Johnston JA, Ward CL, Kopito RR (1998) Aggresomes: a cellular response to misfolded proteins. J Cell Biol 143: 1883-1898

Kaushik S, Massey AC, Cuervo AM (2006) Lysosome membrane lipid microdomains: novel regulators of chaperone-mediated autophagy. EMBO J 25: 3921 - 3933

Kawaguchi Y, Kovacs JJ, McLaurin A, Vance JM, Ito A, Yao T-P (2003) The deacetylase HDAC6 regulates aggresome formation and cell viability in response to misfolded protein stress. Cell 115: 727-738

Kochar DK, Rawat N, Agrawal RP, Vyas A, Beniwal R, Kochar SK, Garg P (2004) Sodium valproate for painful diabetic neuropathy: a randomized double-blind placebo-controlled study. QJM 97: 33-38

Kopito RR (2000) Aggresomes, inclusion bodies and protein aggregation. Trends Cell Biol 10: 524-530

Kumar SK, Rajkumar SV, Dispenzieri A, Lacy MQ, Hayman SR, Buadi FK, Zeldenrust SR, Dingli D, Russell SJ, Lust JA, Greipp PR, Kyle RA, Gertz MA (2008) Improved survival in multiple myeloma and the impact of novel therapies. Blood 111: 2516-2520

Kyle RA, Rajkumar SV (2009) Treatment of multiple myeloma: a comprehensive review. Clin Lymphoma Myeloma 9: 278-288

Mazumder A, Vesole DH, Jagannath S (2010) Vorinostat plus bortezomib for the treatment of relapsed/refractory multiple myeloma: a case series illustrating utility in clinical practice. Clin Lymphoma Myeloma Leuk 10: 149-151

Meregalli C, Canta A, Carozzi VA, Chiorazzi A, Oggioni N, Gilardini A, Ceresa C, Avezza F, Crippa L, Marmiroli P, Cavaletti G (2010) Bortezomib-induced painful neuropathy in rats: a behavioral, neurophysiological and pathological study in rats. Eur J Pain 14: 343-350

Mezey E, Dehejia A, Harta G, Papp MI, Polymeropoulos MH, Brownstein MJ (1998) Alpha synuclein in neurodegenerative disorders: murderer or accomplice? Nat Med 4: 755-757

Mitsiades CS, Hideshima T, Chauhan D, McMillin DW, Klippel S, Laubach JP, Munshi NC, Anderson KC, Richardson PG (2009) Emerging treatments for multiple myeloma: beyond immunomodulatory drugs and bortezomib. Semin Hematol 46: 166-175

Morimoto RI (1998) Regulation of the heat shock transcriptional response: cross talk between a family of heat shock factors, molecular chaperones, and negative regulators. Genes Dev 12: 3788-3796

Munster P, Marchion D, Bicaku E, Lacevic M, Kim J, Centeno B, Daud A, Neuger A, Minton S, Sullivan D (2009) Clinical and biological effects of valproic acid as a histone deacetylase inhibitor on tumor and surrogate tissues: phase I/II trial of valproic acid and epirubicin/FEC. Clin Cancer Res 15: $2488-2496$

Nawrocki ST, Carew JS, Maclean KH, Courage JF, Huang P, Houghton JA, Cleveland JL, Giles FJ, McConkey DJ (2008) Myc regulates aggresome formation, the induction of Noxa, and apoptosis in response to the combination of bortezomib and SAHA. Blood 112: 2917-2926

Ogawa Y, Tobinai K, Ogura M, Ando K, Tsuchiya T, Kobayashi Y, Watanabe T, Maruyama D, Morishima Y, Kagami Y, Taji H, Minami H, Itoh K, Nakata M, Hotta T (2008) Phase I and II pharmacokinetic and pharmacodynamic study of the proteasome inhibitor bortezomib in Japanese patients with relapsed or refractory multiple myeloma. Cancer Sci 99: 140 - 144

Patel PI, Roa BB, Welcher AA, Schoener-Scott R, Trask BJ, Pentao L, Snipes GJ, Garcia CA, Francke U, Shooter EM, Lupski JR, Suter U (1992) The gene for the peripheral myelin protein PMP-22 is a candidate for Charcot-Marie-Tooth disease type 1A. Nat Genet 1: $159-165$

Richardson PG, Badros AZ, Jagannath S, Tarantolo S, Wolf JL, Albitar M, Berman D, Messina M, Anderson KC (2010) Tanespimycin with bortezomib: activity in relapsed/refractory patients with multiple myeloma. Br J Haematol 150: 428-437

Richardson PG, Barlogie B, Berenson J, Singhal S, Jagannath S, Irwin D, Rajkumar SV, Srkalovic G, Alsina M, Alexanian R, Siegel D, Orlowski RZ, Kuter D, Limentani SA, Lee S, Hideshima T, Esseltine D-L, Kauffman M, Adams J, Schenkein DP, Anderson KC (2003) A phase 2 study of bortezomib in relapsed, refractory myeloma. $N$ Engl $J$ Med 348: 2609-2617

Richardson PG, Briemberg H, Jagannath S, Wen PY, Barlogie B, Berenson J, Singhal S, Siegel DS, Irwin D, Schuster M, Srkalovic G, Alexanian R, Rajkumar SV, Limentani S, Alsina M, Orlowski RZ, Najarian K, Esseltine D, Anderson KC, Amato AA (2006) Frequency, characteristics, and reversibility of peripheral neuropathy during treatment of advanced multiple myeloma with bortezomib. J Clin Oncol 24: 3113-3120

Richardson PG, Sonneveld P, Schuster MW, Stadtmauer EA, Facon T, Harousseau J-L, Ben-Yehuda D, Lonial S, Goldschmidt H, Reece D, Bladé J, Boccadoro M, Cavenagh JD, Boral AL, Esseltine D-L, Wen PY, Amato AA, Anderson KC, San Miguel J (2009a) Reversibility of symptomatic peripheral neuropathy with bortezomib in the phase III APEX trial in relapsed multiple myeloma: impact of a dose-modification guideline. Br J Haematol 144: 895-903

Richardson PG, Xie W, Mitsiades C, Chanan-Khan AA, Lonial S, Hassoun H, Avigan DE, Oaklander AL, Kuter DJ, Wen PY, Kesari S, Briemberg HR, Schlossman RL, Munshi NC, Heffner LT, Doss D, Esseltine D-L, Weller E, Anderson KC, Amato AA (2009b) Single-agent bortezomib in previously untreated multiple myeloma: efficacy, characterization of peripheral neuropathy, and molecular correlations with response and neuropathy. J Clin Oncol 27: 3518-3525

Roodveldt C, Bertoncini CW, Andersson A, van der Goot AT, Hsu S-T, Fernández-Montesinos R, de Jong J, van Ham TJ, Nollen EA, Pozo D, Christodoulou J, Dobson CM (2009) Chaperone proteostasis in Parkinson's disease: stabilization of the Hsp70/ $\alpha$-synuclein complex by Hip. EMBO J 28: $3758-3770$

San Miguel JF, Schlag R, Khuageva NK, Dimopoulos MA, Shpilberg O, Kropff M, Spicka I, Petrucci MT, Palumbo A, Samoilova OS, Dmoszynska A, Abdulkadyrov KM, Schots R, Jiang B, Mateos M-V, Anderson KC, Esseltine DL, Liu K, Cakana A, van de Velde H, Richardson PG, for the VISTA Trial Investigators (2008) Bortezomib plus melphalan and prednisone for initial treatment of multiple myeloma. N Engl J Med 359: 906-917

Scuteri A, Nicolini G, Miloso M, Bossi M, Cavaletti G, Windebank AJ, Tredici G (2006) Paclitaxel toxicity in post-mitotic dorsal root ganglion (DRG) cells. Anticancer Res 26: $1065-1070$

Shen S, Zhang P, Lovchik MA, Li Y, Tang L, Chen Z, Zeng R, Ma D, Yuan J, Yu Q (2009) Cyclodepsipeptide toxin promotes the degradation of Hsp90 client proteins through chaperone-mediated autophagy. J Cell Biol 185: $629-639$

Wacker JL, Huang S-Y, Steele AD, Aron R, Lotz GP, Nguyen QV, Giorgini F, Roberson ED, Lindquist S, Masliah E, Muchowski PJ (2009) Loss of Hsp70 exacerbates pathogenesis but not levels of fibrillar aggregates in a mouse model of Huntington's disease. J Neurosci 29: 9104-9114

Watanabe T, Kato H, Kobayashi Y, Yamasaki S, Morita-Hoshi Y, Yokoyama H, Morishima Y, Ricker JL, Otsuki T, Miyagi-Maesima A, Matsuno Y, Tobinai K (2010) Potential efficacy of the oral histone deacetylase inhibitor vorinostat in a phase I trial in follicular and mantle cell lymphoma. Cancer Sci 101: 196-200

Zou J, Guo Y, Guettouche T, Smith DF, Voellmy R (1998) Repression of heat shock transcription factor HSF1 activation by HSP90 (HSP90 complex) that forms a stress-sensitive complex with HSF1. Cell 94: $471-480$ 